\title{
Music as a Tool for Shaping the Growing Individual: A Review
}

\author{
Ernest Francis Amparbin ${ }^{1}$ \\ ${ }_{1}$ Centre for Culture and African Studies, Kwame Nkrumah University of Science and Technology, Kumasi, Ghana.
}

\begin{abstract}
The paper is directed at contributing to the awareness of the need to emphasize the need for music education in schools. Music has largely been touted as a tool for training, however, it is practically being employed as a source of entertainment and a means of engaging learners in the classroom, thereby paying less attention to its evolving effect on the individual. Consequently, a number of literature emphasizing the importance of music as an instrument for the total development of the learner, has been thoroughly reviewed in this paper. This is to expose stakeholders of education particularly educators, policymakers, parents and heads of educational institutions to the inseparable benefits of music in the general education of the learner. It is therefore crucial for teachers and heads of schools to liaise with Parent-teacher associations, non-governmental organizations, School management boards and the Ministry of Education to help furnish schools with appropriate musical instruments and facilities such as sound laboratories, secluded rooms for audio-visuals to aid teachers and learners in the teaching and learning endeavour.
\end{abstract}

\author{
Correspondence: \\ Ernest Francis Amparbin \\ Email: amparbinernest@gmail.com \\ Publication History \\ Received 10th November 2020, \\ Accepted 10th February, 2021, \\ Published online 18th February, \\ 2021.
}

Keywords: Music education, Philosophy of music, Interpretation of music education

\section{INTRODUCTION}

The phenomenon "Music" as created by nature seems to have a direct connection with the soul and body of every living organism with special reference to Humans. Since the future of the current generation depends on children, the focus of this paper will dwell much on them especially the school children or students. Without a doubt, the Author is of a resolute view that all students or children need a strong foundation in music education. Gehrkens is of the view that "Music for every child, every child for music." ${ }^{1}$ Per this statement, one would not be far from right in suggesting that because children are "malleable" music plays a major role in developing them holistically for the sustenance of the future. This write-up therefore seeks to discuss music as can be adopted for the development of the individual with specific reference to children.

\section{Music as a tool for development}

Many definitions have been given to the term music. The simplest thought would be a combination of different sounds that pleases the ears. Though this answer given seems very precise, it might differ from one culture to the other. Thus, Okantah poses this question, "has it ever struck any of you that what might be called music in one culture might sound like noise in another?" 2 In like manner, Verrastro suggests that:

Music as known in the Western world today exists as a genre significantly different from its equivalent in other cultures. Beyond the obvious differences of tonal structure, instruments cultural utilizations, styles and the like, Western music is polyphonic by design. This is not true of many of the music of non-Western cultures. ${ }^{3}$

\footnotetext{
Karl W Gehrkens, "President's Corner”. Music Supervisors'Journal, 9, no 4 (1923), 6-10.

2 Michael Ohene-Okantah, "Music in Ghanaian Education; In Search of a National Philosophy" Paper presented at Annual National Conference of the Ghana Music Teachers Association, Akropong Akwapim, 25 $5^{\text {th }}-28^{\text {th }}$ August, 1997.

Ralph Verrastro, "The Aesthetic Foundation of Music Education” The Canadian Journal of Music education, 31 , no. 3 (1990).
} 
The observation of Verrastro emphasizes the fact that music really differ from various cultures though certain basic elements of music (melody, timbre, pitch and the like), may cut across. Music in the words of Ohene- Okantah is "organized sounds and silence within the cultural context". ${ }^{4}$ He further expatiates that the idea of music in the African cultural milieu involves a lot more than structured expressive sounds akin to felt life. Okantah is of the view that music in the African sense goes beyond drumming and dancing and agrees with Bebey who pulsates that much of the African music is founded on speech such that the bond between language and music makes room for an instrument to be tuned for music and further produced linguistically and comprehensibly. ${ }^{5} \mathrm{He}$ concludes that what constitutes music to the African is not only the tune but also the words, the philosophical ideas and the dance steps that accompany it. Indeed, the personal experience of the writer as a music educationist and his encounter with music teachers and teachers in general particularly those at the lower classes in the basic schools, indicate that teachers and learners have an appreciable affinity for music, as they regularly explain how beneficial music and musical activities have been to them in the teaching and learning processes. Notwithstanding, the teachers mostly expressed concern about the lack of appropriate and required quantity of musical instruments for effective teaching and learning in the schools. They also complained of the absence of regular workshops, seminars and outreaches to equip them to give off their utmost best in providing the learners with the needed skills.

Though music education and the organization of musical activities in schools and communities are saddled with challenges, it is a common scene in the Ghanaian or African setting to find a group of people or children enjoying music of a sort in the open in their own way. This is because it is perceived that music helps in easing numerous personal challenges such as emotional distress, pain, limb coordination, etc. In this perspective, Miche poses the question; "what would one's life be like, without music?" ${ }^{6}$ In a typical African society, growing up as a child would have been one great boring activity if there were no songs, rhythms, dancing, the beating of drums, and the ringing of bells. Then also later in life, one can imagine what would have happened to a Ghanaian youth if he was denied the merits of storytelling and singing around campfires, music in church, teen romance songs, bands and dances, though in recent times playing of computer games and the use of interactive programmes in various homes seem to have taken over the organization of traditional musical activities in the urban centers.

Additionally, Bray indicates that music is a unique form of communication that can change the way students feel, think and act. ${ }^{7}$ Music as an integral part of culture both in past and present helps students to understand themselves and relate better with others. Furthermore, music can be described as the satisfaction a person derives as a performer or a consumer of the music of a particular cultural context since culture forms a significant factor in forming human consciousness. Culture and its music contribute greatly to the formation of beliefs and values of its members because music from different cultures reflects different concepts that are unique to each culture. The Tanglewood Symposium of 1967, agitated for the inclusion of multicultural music in the music curriculum for the reason that Music had been found to offer a wide range of ways to progress intellectually, as in the case of other causes. Intellectual advancement comprises imagination, culture, individuality, opportunity, feelings, and the composure of one's self. With the inclusion of composition, performance, improvisation, listening, music theory, musicology, and music teaching in the music curriculum, it is expected that the learners would achieve their maximum potentials with music fulfillment.

Touching on the effect of music on human development, Bray indicates that music is considered to be a powerful and unique form of communication that can change the way students feel, think and act. ${ }^{8}$ Music unites intelligence and meaning and permits individual mien, comprising thinking and emotional expansion. How much music is essential to culture, aids learners to appreciate each other and ensure the connection of the immediate habitat, school and the community at large. Music education develops students and teachers and instills in them the capability to decipher between musical types. Consequently, regular participation in musical activities builds in the individual the feeling of self-reliance, we-feeling, aesthetic and creative empowerment.

\section{Music Education}

In an attempt to explain the import of education, Dewey mentions that it is a fostering, nurturing, and cultivating process to acquire a transformation, of the quality of experience till the newest member of the social group is ready to partake in the interest, purposes and destination of the lager group. ${ }^{9}$ Education as observed by Plato and alluded to, by Amparbin is also explained as turning the eye of the soul from darkness to light. ${ }^{10}$ Kpeglo, elaborates the submission on education

\footnotetext{
Ohene-Okantah, "Music in Ghanaian Education".

Francis Bebey, African Music; A people's Arc (Bennett, J. tr. New York; Lawrence Hill and Company, 1975).

Mary Miche, Weaving Music in to Young Minds. USA. Delmar, Thomson Learning Incorporated. (2002), 1.

David Bray, Teaching Music in the Secondary School (Jordan Hill Oxford.Heinemann Educational Publishers Halley Court, 2002).

Bray, Teaching Music in the Secondary School.

John Dewey, the School and Society, Chicago. (Chicago: University of Chicago Press, 1929).

10 Ernest Francis, Amparbin, The use of songs in the teaching and learning process of early childhood: A study of selected schools in the Oforikrom Sub-metro of the Ashanti Region, (Winneba: University of Education, 2015).
} 
to mean leading a person from the dark cave of ignorance into the limelight of knowledge. ${ }^{11} \mathrm{He}$ further observed that the act does not involve putting knowledge in a person's soul as one puts water into an empty pot, rather it is aiding the person to realize knowledge through his own reasoning processes. ${ }^{12}$ Certainly, if one would not be wrong in accepting the thought expressed as some of the qualities of education, then the general comment that education is the key to success, must indeed be a watchword for every individual, group, society, community and the nation as a whole. Thus, Music education implies the acquisition of musical knowledge through the processes of imparting and absorbing it in either a formal or informal setting. Gabrieli stated that mastering (learning) a musical instrument improves the way the human brain processes parts of spoken language. ${ }^{13}$ It is also an undoubtable assertion by Trainor that, young children who take music lessons show different brain development and improved memory over the course of a year, compared to children who do not receive any musical training. Musically trained children perform better in a memory test that is correlated with general intelligence skills such as literacy, verbal memory, visio-spatial processing, mathematics and intelligent quotient. ${ }^{14}$ On this, Gabrieli explains that children could benefit more if formal music education is introduced into school education. ${ }^{15}$ Looking in the direction of benefits, one could consider several avenues such as music to the individual, the church, at workplaces, music as a means to an end, as a tool of social change, as a medium of communication just to mention.

The societal perception about music has always seemed exigent, therefore the assumption is that one needs to be endowed with special qualities such as endurance, control over limbs to be able to undergo music tutorials of a standard level. In the end, the knowledge acquired is enormous and applicable to other subject areas. In this vein, Gabrieli mentioned that "using Functional Magnetic Resonance Imaging (FMRI), researchers also discovered that musical training helps the brain to work more efficiently in distinguishing split-second differences between rapidly changing sounds that are essential to processing language." ${ }^{\prime 16}$ Linking the view of Gabrieli to the Ghanaian educational system, the realisation is that children could even benefit more if formal music education is introduced at the pre-school level with emphasis on listening and performing.

The report of the Children's Music Workshop 2017 suggests that music uses both sides of the brain. ${ }^{17}$ This is a fact that makes music valuable in all areas of development. It has a strong effect on the growth of the child's brain academically, emotionally, physically and spiritually.

Though there are different avenues where music functions have been identified, the focus will still be directed to the school since the school is one huge institution meant for churning holistic humans for the future. As part of the development which is the core function of the school, Miche observed that music education is as important for the development of a whole child as it is in the development of one's own life. ${ }^{18}$ The teacher's work will be to provide a musical environment to aid the natural development of the child's musical ability and neural growth.

Music education as Bray recounted, provides opportunities for learners to develop the key skills of:

1. Communication, by presenting music to a diverse audience and discussing and sharing ideas with others.

2. Application of numbers, through recognizing patterns, sequence, order and rhythmic relationships.

3. Information technology, with the use of a range of ICT to compose and perform music

4. Working with others, by taking different roles and recognizing and supporting the different contributions of others in group and ensemble work.

5. Improving own learning performance, through appraising their own work, recognizing the need for perseverance, developing the ability to use time effectively, and increasing their ability to work independently.

6. Problem solving, through achieving intentions when composing and presenting performances to different audiences and in different venues. ${ }^{19}$

The National Content Standard of the U.S in Music Education also requires that a comprehensive music education over a period must result in one's ability to:

1. Perform alone and with others, a varied repertoire of music

2. Improvise melodies, variations and accompaniments

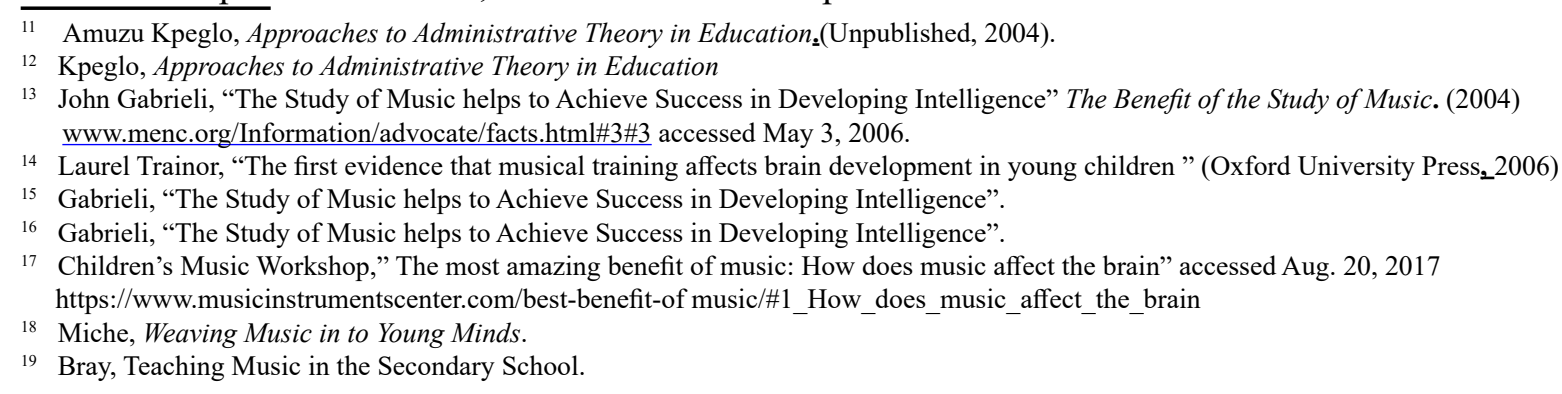


3. Compose and arrange music within specified guidelines

4. Read and notate music

5. Listen and analyze music

6. Evaluate music and music performance

7. Understand relationships between music, the other arts, and disciplines outside the arts

8. Understand music in relation to history and culture. ${ }^{20}$

The perception of writers about the fact that music permeates other subject areas of study is another reason why authorities of education find it expedient to introduce music in the curriculum of schools. In light of this, Schmidt holds the view that music has a tremendous value as an academic discipline because it contributes to the understanding of other subjects. ${ }^{21}$ Schmidt continues that there is a big difference between learning about something and doing it, but with music, both processes apply.

It is in this vein that Winslow expresses the observation that education in music is most sovereign, because more than anything else, rhythm and harmony find their way into the secret places of the soul. ${ }^{22}$ Winslow further explains that music correlates naturally and readily with most of the subjects in the school curriculum especially in the Fine Arts, poetry, drawing, painting, dance, drama, and social studies. Indeed music is not a frill to be added to the daily schedule "if time permits" but should be a regular educational process in the learner's development. It is the view of Winslow that people participate in music more effectively than they use their minds in mastering symbols in formal academic programmes. According to Johnson and Memmott, students in schools that had excellent music programs had higher English and Mathematics test scores across the country than students in schools with low-quality music programs. They maintained that students in top-quality music programs scored $22 \%$ better in English and 20\% better in mathematics than students in schools with deficient music programs. ${ }^{23}$ With formal education, music is perceived to be a catalyst to learning and mental development. Menc opines that music education is a lifelong process involving students at all levels. ${ }^{24}$ Music serves a special body to an academic structure's of knowledge, skills and unique ways of knowing and thinking. ${ }^{25}$

Undoubtedly, in the arts, music has particularly been professed to be at the forefront of enhancing teaching and learning of other subjects. In response to the concern over the looming educational imbalance, the American Association of School Administrators chose the theme "The Creative Arts in Education" for its 1959 Convention. ${ }^{26}$ At the meeting, a resolution was passed that all school systems should strive to maintain a well-balanced school curriculum in which music, drama, painting, poetry, sculpture, architecture and the like are included side by side with other subjects such as mathematics, history, science. ${ }^{27}$ Bessom and Tatarunis, maintain that it is important that learners as a part of general education learn to appreciate, understand, create and criticize with discrimination those products of the mind, voice, hand and the body which give dignity to the person and exalt the spirit of man. ${ }^{28}$ Additionally, they also opine that the support for music education which came from the National Association of Secondary School Principals in a position paper published in 1962, stressed the need for a balanced curriculum and the importance of the arts as part of the comprehensive high school. ${ }^{29}$ This is because the arts are perceived to be subject disciplines that emphasize the use of the intellect as well as the development of sensitivity, creativity and the capacity to make reasoned aesthetic decisions in extending the range of human experience. The arts give directions to man's pattern of living from the setting of his table to the expression of his most cherished aspirations. Furthermore, the arts constitute a vast communication system that compliments man's cognitive word system. ${ }^{30}$ Giunta indicates that "a balanced attitude toward lifelong learning should be cultivated in every person." ${ }^{\prime 31}$

He goes on to emphasize that:

The benefits of music education have been well-documented and should be considered a necessary component of the curriculum of every child. Music should be included in the recreational activities of every adult as well. Music does not have to displace other activities, but can be worked into a schedule even if only twenty minutes a day are

\footnotetext{
20 The National Standards for Music Education, “A transdisciplinary approach in the applied studio” Music Educator's journal 97, no 2 (2010) 44-50. 1 Ian Schmidt, Basics of Singing. (Macmillan Publishing Company, New York, 1989).

2 Robert W. Winslow, Music Skills for Classroom Teachers. (Brown Publishing Company USA. Wm C, 1992)

3 Jenny .E. Memmott \& Christopher .M. Johnson, “Achievement of Success in School and Learning”. Benefits of the Study of Music. (2006).

4 Music Educator's National Conference, A Research Agenda for Music Education. (1998) http://www.menc.org accessed March, 2008

5 Bennett Reimer, A Philosophy of Music Education Advancing the Vision. (Prentice-Hall. Englewood Cliffs, New Jersey. 2003).

26 Malcolm E. Bessom \& Alphonse .M. Tatarunis, Teaching Music in Today's Secondary School. (NY._Holt, Rinehart and Winston Inc.1980).

Bessom \& Tatarunis, Teaching Music in Today's Secondary School

Bessom \& Tatarunis, Teaching Music in Today's Secondary School.

Bessom \& Tatarunis, Teaching Music in Today's Secondary School

Bessom \& Tatarunis, Teaching Music in Today's Secondary School.

John P Giunta. "A Philosophy of Music Education; my music teaching philosophy”, specialmind,com/musicEd.htm (2006), accessed Oct. 10, 2009.
} 
available. Every effort should be made to find ways to incorporate the various components of the music lesson metaphorically into the rest of our lives. The lessons from music study are various: patience, problem-solving, creativity, self-expression, concentration and memorization. ${ }^{32}$

It is assumed that individuals are usually encouraged to avail themselves to be schooled musically in order to acquire the unique benefits that music has for learners toward one's future. In line with this view, Reimer explicitly states that; ...the objectives of general music education are to improve musical perception, encourage musical reaction, enhance musical creativity through more expert and sensitive performance, composition and improvisation, increase the depth and breadth of concepts about the art of music and how it works, develop analytical abilities and promote more refined evaluations of music. ${ }^{33}$

Music mostly involves the creation and presentation of these activities to enhance the creative and aesthetic abilities of the individual. As a result, a good educational programme in music and dance provides learners with greater opportunities, exposure and experiences for developing their creative skills. The Music and Dance Syllabus for Basic Schools, explains creativity as the ability to produce novel work that is accepted as tenable, useful and satisfying by a group at a point in time. ${ }^{34}$ However as indicated earlier, music and dance include composition, improvisation, originality, recreation and interpretation of existing works. Aesthetic sensitivity on the other hand deals with the individual's response to the expressive qualities of the arts. It entails the development of an attitude that promotes initiative and the desire to continue to participate in and value the performing arts. The aesthetic sensitivity has affective qualities which consist of several learning and behavioral levels such as receiving, responding, valuing and organizing. The behavior at the receiving level is the ability to follow directions, listen to music, show awareness and sensitivity, accept, and ask questions on music and dance. ${ }^{35}$

The proposed Senior Secondary School Music Syllabus also describes music as "an aesthetic art which is valued and appreciated by every society." 36 Furthermore, in Ghana, music permeates the way of life because it is performed on different occasions and ceremonies such as puberty rites, marriage, death, religion, birth rites and festivals. It plays a vital role in political events and national days, hence, its importance in the curriculum. The general objectives have therefore been that the students should be able to: perform reasonably well as soloists on an instrument or as singers, participate by playing an instrument or singing in an ensemble, compose short pieces for a solo instrument including voice, know the history, social and economic factors that have influenced composers and musicians to write their music, discuss the contributions of selected composers and musicians to the development of music, identify the major characteristics of pieces of music heard, appreciate and talk intelligently about music. ${ }^{37}$ The role of the arts particularly music and dance in the Ghanaian (African) society and its school curriculum is understood to give a unique identity to the society and its people. Langer thus asserts that "The arts objectify subjective reality and subjectify outward experience of nature. Art education is the education of feeling and a society that neglects it gives itself up to formless emotion." 38 Again, Langer identifies special values of music in the school curriculum as individualization, aesthetics, socialization, correlation and remediation. On individualization, the view is that once music conveys various meanings, it has something for every learner because, with the numerous activities of the music class like singing, moving, playing of instruments, composing and the like, a child can identify at least an activity which can give him a feeling of success. The child could react differently from his peers to a musical experience without fear of failure. In an effective music class individual reactions are encouraged and valued and this aids self-identification and self-esteem on the part of the learner. Aesthetically, music gives satisfaction as compared to other arts because it has the power of evoking feelings that are salient to the child's knowledge of beauty.

Being sensitive to music and other arts enhances one's self-awareness and relation to other people. More so, when one considers the modern world without music, then the child's potential loss in never knowing about music becomes evident. Music may sometimes appear to be an effective socializing tool, the reason being that most often, children may experience music together as they sing and dance, play instruments, or even compose and work in ensembles where they learn to accept one another in role-playing. The view on correlation as explained by Langer looks at a teacher who is endowed with musical skills and the vast abilities to fuse music with other curricular areas. ${ }^{39}$ For instance, the teacher aids the learners to understand the culture of another country by guiding them to listen, appreciate and perform folk songs and dances of that country. In respect of remediation, Langer establishes the view that there is a growing awareness of the importance

${ }_{32}$ Giunta, A Philosophy of Music Education.

33 Reimer, A Philosophy of Music Education

34 CRDD Teaching Syllabus for Music and Dance. (Accra-Ghana Basic Schools. Ministry of Education, 2000).

${ }_{35}$ CRDD Teaching Syllabus for Music and Dance.

${ }^{36}$ CRDD Proposed Senior High School Syllabus for Music. (Accra-Ghana Ministry of Education, 1990), 1.

37 CRDD Teaching Syllabus for Music and Dance.

38 Susan K Langer Philosophical Sketches. (New York. Harper and Row Publishers, Inc. 1964), 110.

39 Langer Philosophical Sketches, 110. 
of music in working with special problems such as children who are slow learners, emotionally disturbed, or physically handicapped. ${ }^{40}$ Under umbrellas such as "music therapy" or "music in special education", special emphasis is being placed on the use of music. Many of these children are now being placed in mainstream elementary classrooms, where musical activities have proven to be very effective with them.

Gardner, through the theory of multiple intelligences that identifies music as a separate intelligence, suggests that people learn in seven different ways and that there are certain specific bits of intelligence that different people have which affect how they learn best. ${ }^{41}$ According to Gardner, musical intelligence consists of skill in performance, composition, and appreciation of musical patterns; it encompasses the capacity to compose and recognize different musical tones, pitches, and rhythms. Music teaches how to learn through sounds, exercise creativity, and experience emotions. $^{42}$

\section{Philosophy of music education}

It is remarkably essential for individuals, groups and possibly institutions to have an identity and for this reason, usually, groups and individuals of a particular faith prefer to be identified with certain words and phrases. An example is "Jah Rastafari" used by and for the Rastafarians, and colours and dress codes with a particular hairdo for members of Krishna Consciousness Society to mention a few. All these codes of identity are aimed at toeing a particular philosophical ideology. The American Heritage Dictionary of English Language describes "Philosophy" as a system of values by which one lives thus a set of ideas or beliefs relating to a particular field or activity, the discipline comprising logic, ethics, aesthetics, metaphysics, and epistemology. ${ }^{43}$ Similarly, the Collins English Dictionary explains "Philosophy" as the academic discipline concerned with making explicit the nature and significance of ordinary and scientific beliefs and investigating the intelligibility of concepts using rational argument concerning their presuppositions, implications, and interrelationships; in particular, the rational investigation of the nature and structure of reality (metaphysics), the resources and limits of knowledge (epistemology), the principles and import of moral judgment (ethics), and the relationship between language and reality (semantics). ${ }^{44}$ Furthermore, it is the particular doctrines relating to the issues of some specific individual or school, that characterizes the critical study of the basic principles and concepts of a discipline.

Opinions seem to differ from one person to the other in respect of what Philosophy really is therefore, in an attempt to clarify thoughts about philosophy Pecorino, suggests that:

Philosophy is not a picking and choosing what body of thought one would like to call one's own or would like to believe in; a choice based upon personal preferences or feelings. Philosophy is a pursuit. One can choose to be philosophical. One can choose to be a philosopher. One can NOT choose a Philosophy. Philosophy, insofar as it may be correlated at all to a "way of Life", is a form of thinking meant to guide action or to prescribe a way of life. The philosophic way of life, if there is one, is displayed in a life in which action is held to be best directed when philosophical reflection has provided that direction; e.g., SOCRATES the paradigm of a philosopher. ${ }^{45}$

He explains that Philosophy is an activity of thought, the most critical and comprehensive manner of thinking which the human species has yet devised. This intellectual process includes both analytic and synthetic mode of operation. In this perspective, one would not be far from right in postulating that Philosophy involves resolving confusion, unmasking assumptions, revealing presuppositions, distinguishing importance, testing positions, correcting distortions, looking for reasons, examining world-views and questioning conceptual frameworks. It also includes dispelling ignorance, enriching understanding, broadening experience, expanding horizons, developing imagination, controlling emotion, exploring values, fixing beliefs by rational inquiry, establishing habits of acting, widening considerations, synthesizing knowledge and questing for wisdom. ${ }^{46}$

The possible indication one can deduce from the various incursions to establish the import of philosophy so far is directed towards the existence of humans. There is nothing in man's existence which is more than life and in the same manner, nothing in life supersedes philosophy. This is because philosophy seeks to critic the meaning of Man's existence, for example, nature, purpose, meaning, destiny and above all the origin of mankind. In philosophy, the word "Logic" functions prominently in that rational speculation involving logical reasoning in analyzing thoughts and phenomena are paramount.

Society and dynamics seem inseparably bound. This is to say that conditions regarding lifestyle, upbringing methods,

$40 \quad$ Langer Philosophical Sketches.

41 Howard Gardner, Frames of Mind: The theory of multiple intelligences (New York: Basic Books New York: Harper Collins College Publishers, 1983.

42 Gardner, Frames of Mind: The theory of multiple intelligences.

43 The American Heritage Dictionary of the English Language. (Fourth Edition copyright by Houghton Mifflin Company, 2009).

44 Collins English Dictionary - Complete and Unabridged. (HarperCollins Publishers, 2003).

45 Philip A Pecorino, “Just what is Philosophy, anyway?' class notes intended to comment on readings and amplify class discussion. Web Surfer's Caveat,(2000).

46 Pecorino, "Just what is Philosophy, anyway? 
and living standards changes with time, so it is with philosophy. Though Reimer considers these changes as limitation of philosophy, he maintains that:

Some philosophy, some underlying set of beliefs about the nature and value of one's field, is required if one is to be effective as a professional and if one's profession is to be effective as a whole. Indeed, a continuing need of the profession is a statement of philosophy which captures the sense where the profession stands and where it is going and which provides a common point of reference from which new and differing ideas can spring. ${ }^{47}$

He noted further that the impact of the profession on society depends to a large extent on the worth of the profession's standing of what it has to offer which might be of value to society. There is a need for a better understanding of the value of the teaching and learning of music. As result, the modern-day educational system encourages thorough scrutiny of every facet of public education.

The foundation of philosophy including music education, must answer the question about "why". It is believed that a large part of the answer to this question relates to the way music is part of the physiological makeup and how it is deeply expressed naturally in even the breathing, walking and heartbeat of man. ${ }^{48}$ Reimer suggests a philosophy of music education as cited by Okantah that;

1. Individuals who make up the profession need a clear notion of their aims as professionals and a conviction of the importance of those aims. Individuals who have a convincing justification of music education... Exhibit in their own lives the inner sense of worth which comes from doing important work in the world.

2. The understanding people have about the value of their profession, inevitably affect their understanding of the value of their personal lives.

3. Music teachers in preparation need an understanding of the importance of their chosen field. It gives them a sense of purpose, a sense of mission and meaning to their professional lives.

4. Necessary for the development of self -identity and self-respect, it will promote and channel commitment and dedication to music education.

5. It serves as a guide for daily professional decisions and choices. Without a clear understanding, teacher's decisions and choices are rather idiosyncratic. The deeper the understanding, the more consistent, the more focused, the more effective the teacher's choices.

6. A philosophy helps in the formulation of objectives.

7. It also helps to establish the place of music and the other arts as the basic way that humans know themselves and their world; a basic model of cognition. ${ }^{49}$

Additionally, Reimer opines that philosophy must articulate a consistent and helpful statement about the nature and value of music and music education. ${ }^{50}$ A philosophy of music education should establish that music offers values unattainable in other subjects and that such values are very important for all and sundry.

\section{An interpretation of music education}

The discussion on the philosophy of music education so far portrays the philosophy to be carefully selected and orchestrated phrases and sentences to tailor the work or activities of the individual or group to achieve a goal. In like manner, as a music educationist (teacher) this researcher considers music for all and all for music especially children and their developmental stages. This is because humans 'particularly children at very young ages demonstrate instinctual impulses to sing, no matter the cultural environment. Some music educators like Lehman contend that music exists in the brain and can actually be considered as a separate type of thinking process. ${ }^{51}$ Music seems to be processed in many different parts of the brain and not simply concentrated in the right or left hemisphere like math or language skills. ${ }^{52}$ Liegeois-Chauvel, et.al add that the brain processes music stimuli while producing emotions, but leaves one without a way to describe the process or experience with symbols or words. For example in the Western music tradition, the need or desire to coalesce around a tonic note or key is a visceral, not language-thought-induced reaction. Perfect pitch and various forms of synesthesia are even more evidence that the brain can treat music as a unique form of cognitive processing.

The value of music in the life of humans is very vital so far as holistic development is concerned. Lehman,

\footnotetext{
47 Reimer, A Philosophy of Music Education,

48 Reimer, A Philosophy of Music Education.

49 Reimer, A Philosophy of Music Education.

50 Reimer, A Philosophy of Music Education.

51 Paul R. Lehman, Why teach music in school? Remarks prepared for the public relations video presentations of the Gemeinheardt Company, Inc., Elkhart, Indiana (1995, September).

52 Catherine. Liegeois-Chauvel, I., Peretz, M., Babai, V., Laguitton, \& P. Chavel, "Contribution of different cortical areas in the temporal lobes to music processing". Brain, 121, (1998) 1853-1867.
} 
explains that music instruction and experience can help to develop, "out-of-box," thinking. This type of thinking can be useful in a world where many issues are not black and white. ${ }^{53}$ It is believed that music studies in schools and at home provides students with an opportunity to develop unique cognitive thought processes as well as the psychomotor and affective domains. For instance listening to music, analyzing, creating music, playing musical instruments all involve cognitive, psychomotor and affective strategies that are transferable to other tasks both at home and school. As a result, teachers could collaborate with other music professionals possibly outside academia to share experiences to enrich their skills. The collaboration may be facilitated by Music educators with the use of electronic media to bring the world to the students when field trips are not possible. Peer teaching amid departments in schools could be an innovative means to bring in new perceptions. Additionally, stronger ties should be established with higher institutions such as universities and polytechnics to foster a variety of research in different areas.

Since the philosophy stated caters for all manner of persons with special reference to children, it is very crucial to consider the nature of music for the special children on the special education programme. It is a bit doubtful for any individual or persons to mandate any kind of music to the special children in the special schools. This is because they all have different status of challenges

Therefore Music may be contraindicated for some disabilities or syndromes and would trigger unwanted behavior issues. For Children with disabilities to be mainstreamed into regular music classes, the services of a music therapist will be required. The consultant will ensure that the placement will be good for the child and not rather take away the musical experience of the rest of the students. Music therapists will need to be prominently available as resource persons for music educators as more special education students become mainstreamed into regular education classes. When necessary, it may be more effective to have the music therapist teach individual adapted music lessons with the music educator acting as a consultant. Junior high and Senior high school students with disabilities could benefit from a "circle of friends" or peer partners to help with placement in music class or ensembles. Special roles may also be explored so that any interested special education student can participate, even if it is as an office assistant or on the sidelines in the "pit" for the marching band.

For music and music education to grow to bring its benefits to the doorstep of the society, this researcher suggests that some schools could be allowed to run core music programs and a selection of specialized music courses, where courses would among other things emphasize listening and performance ahead of composition and music literature as part of the instruction. The music repertoire should center on both African and western civilization with occasional study of world music.

\section{CONCLUSION}

Music is valuable because of its intrinsic nature within humanity and human cultures, and has become a part of the makeup of society. Thus the teaching of music must be encouraged and continued as part of the fundamental curriculum in schools with highly trained teachers who are open to change and collaboration. Outreaches should be increased to non-traditional and special education students and more opportunities for music programs beyond the band, orchestra and choir. Music should be offered to all secondary level students irrespective of its form. Music as part of the fabric of humanity and culture is an essential part of the experience, knowledge and practice and should have its place among the core subjects taught in schools.

\section{ABOUT AUTHOR}

Ernest Francis Amparbin, M.Ed, MPhil (Music Education), PhD candidate, Chief Technician (Music), Centre for Culture and African Studies, Kwame Nkrumah University of Science and Technology, Kumasi, Ghana.

\section{BIBLIOGRAPHY}

Amparbin, Ernest Francis., The use of songs in the teaching and learning process of early childhood: A study of selected schools in the Oforikrom Sub-metro of the Ashanti Region, Winneba: University of Education, 2015.

Bebey, Francis., African Music; A people's arc (Bennett, J. tr.) New York; Lawrence Hill and Company. 1975.

Bessom, Malcolm, E. \& Tatarunis, Alphonse. M. Teaching Music in Today's Secondary_School, NY.Holt, Rinehart and Winston Inc 1980.

Bray, David. Teaching Music in the Secondary School. Jordan Hill Oxford. Heinemann Educational Publishers Halley Court, 2002.

Curriculum Research and Development Division, Teaching Syllabus for Music and Dance, Accra-Ghana Basic Schools. Ministry of Education, 2000.

\footnotetext{
53 Lehman, Why teach music in school?
} 
Curriculum Research and Development Division Proposed Senior High School Syllabus for Music, Accra-Ghana, Ministry of Education, 1990.

Collins English Dictionary - Complete and Unabridged HarperCollins Publishers, 2003.

Children's Music Workshop, "The most amazing benefit of music: How does music affect the brain" accessed Aug. 20, 2017. https://www.musicinstrumentscenter.com/best-benefit-of-music/\#1_How_does_music_affect_the_brain

Dewey, John. "The School and Society”, Chicago. (Chicago: University of Chicago Press, 1929).

Gabrieli, John. "The Study of Music helps to Achieve Success in Developing Intelligence" The Benefit of the Study of Music, 2004.

Gardner, Howard. Frames of Mind: The theory of multiple intelligences, New York: Basic Books New York: Harper Collins College Publishers, 1983. https://doi.org/10.1002/pam.4050030422

Gehrkens, Karl .W, “President's Corner”. Music Supervisors'Journal, 9, no 4 (1923), 6-10. https://doi.org/10.2307/3382290

Giunta John. P. “A Philosophy of Music Education; my music teaching philosophy”, (2006), accessed Oct. 10, 2009. www.specialmind.com/musicEd.htm

Kpeglo-Amuzu, Approaches to Administrative Theory in Education ${ }_{2}$ Unpublished, 2004.

Langer .Susan, K., Philosophical Sketches. New York. Harper and Row Publishers, Inc. 1964.

Lehman, Paul. R. Why teach music in school? Remarks prepared for the public relations video presentations of the Gemeinheardt Company, Inc., Elkhart Indiana, September, 1995.

Liegeois-Chauvel, Catherine. Peretz, I., Babai, M., Laguitton, V., \& Chavel, P., Contribution of different cortical areas in the temporal lobes to music processing. Brain, 121, 1853-1867, (1998). https://doi.org/10.1093/brain/121.10.1853

Memmott, Jenny, E and Johnson, Christopher, M, Achievement of Success in School and Learning, Benefits of the Study of Music. 2006. www.menc.org/information/advocate/facts.html\#2\#2 accessed June, 2008

Miche, Mary. Weaving Music in to Young Minds. USA. Delmar, Thomson Learning Incorporated, 2002, 1.

Music Educator's National Conference, A Research Agenda for Music Education, (1998). Accessed March, 2008, http://www.menc.org

Okantah, Michael, .O. "Music in Ghanaian Education; In Search of a National Philosophy" Paper presented at Annual National Conference of the Ghana Music Teachers Association, Akropong Akwapim, $25^{\text {th }}-28^{\text {th }}$ August, 1997.

Pecorino Philip, A “Just what is Philosophy, anyway?' class notes intended to comment on readings and amplify class discussion. Web Surfer's Caveat: They should be readas such. All Rights reserved, 2000.

Reimer, Bennett. A Philosophy of Music Education: Advancing the Vision. Prentice-Hall. Englewood Cliffs, New Jersey. 2003.

Schmidt, Ian. Basics of Singing. Macmillan Publishing Company, New York, 1989.

The American Heritage Dictionary of the English Language, Fourth Edition, Boston: Houghton Mifflin Company, 2009.

The National Standards for Music Education, "A transdisciplinary approach in the applied studio" Music Educator's Journal 97, no 2 (2010) 44-50.

Trainor, Laurel. "The first evidence that musical training affects brain development in young children" Oxford University press, (2006).

Verrastro, Ralph. The Aesthetic Foundation of Muisc Education. The Canadian Journal of Music education, 31, no. 3(1990).

Winslow, Robert. W. Music Skills for Classroom Teachers. Cincinnati: Brown Publishing Company, 1992. 